\title{
Family history in stone disease: how important is it for the onset of the disease and the incidence of recurrence?
}

\author{
Hakan Hasbey Koyuncu • Faruk Yencilek • \\ Bilal Eryildirim $\cdot$ Kemal Sarica
}

Received: 20 June 2009 / Accepted: 10 December 2009 / Published online: 15 January 2010

(C) The Author(s) 2009. This article is published with open access at Springerlink.com

\begin{abstract}
The aim of this study was to evaluate the possible effect of a positive family history on the age at the onset of urinary stone disease and the frequency of subsequent symptomatic episodes relating to the disease. Between March 2006 and April 2009, patients with either a newly diagnosed or a previously documented stone disease were included in the study program. They were required to fill in a questionnaire and divided into two groups according to the positive family history of stone disease; group I comprised patients with a family history for urinary calculi and group II those without. Depending on the data obtained from questionnaires, all patients were evaluated in detail with respect to the age at the onset of the stone disease, stone passage and interventions over time, time to first recurrence (time interval between the onset of the disease and the first recurrence), number of total stone episodes and recurrence intervals. 1,595 patients suffering from urolithiasis with the mean age of 41.7 (14-69 years) were evaluated with respect to their past history of the disease. There were 437 patients in group I and 1,158 in group II. There was no statistically significant difference between the mean age value of two groups $(P=0.09)$. When both genders in group I were analyzed separately, female patients tended to have higher rate of family history positivity than males. Comparative evaluation of the age at the onset of the disease between the two groups did reveal that stone formation
\end{abstract}

H. H. Koyuncu $(\bowtie) \cdot$ F. Yencilek · K. Sarica

Department of Urology, Yeditepe University Medical School, Devlet yolu Ankara Cad. 102/104, Kozyatağı,

34752 Istanbul, Turkey

e-mail: hakan.koyuncu@yeditepe.edu.tr

B. Eryildirim

1st Urology Department,

Kartal Training and Research Hospital, Istanbul, Turkey occured at younger ages in patients with positive family history $[P=0.01$ (males), $P=0.01$ (females) $]$ and the mean age of onset of the disease was lower in males than females in group I $(P=0.01)$. Patients in group I had relatively more stone episodes from the onset of the disease $[P<0.01$ (2-4 episodes), $P<0.01$ ( $\geq 5$ episodes)]. Male patients were associated with higher number of stone episodes $(P=0.01)$. Mean time interval between recurrences was noted to be significantly shorter in group I patients when compared with patients in group II $[P<0.01$ (males), $P=0.02$ (females)]. In conclusion, our results showed that urinary stone formation may occur at younger ages and that the frequency of symptom episodes may be higher in patients with a positive family history. We believe that the positive family history for urinary stone disease could give us valuable information concerning the onset as well as the severity of the disease.

Keywords Urolithiasis · Onset age · Family history

\section{Introduction}

With a constantly increasing incidence, urolithiasis has an estimated lifetime risk between 5 and $12 \%$ in Europe as well as in USA, affecting $13 \%$ of men and $7 \%$ of women populations $[1,2]$. Because a considerable percent of patients will have a recurrence of renal colic within 5 years after the first stone episode, urolithiasis can be accepted as a chronic disease, with substantial economical consequences and great public health importance. The prevalence is increasing, on average 5\%, ranging from 4 to $10 \%$ in different studies [3, 4]. Following the onset of the disease, the average recurrence rate is $31.5-50 \%$ within 5 years and more than $72 \%$ after 20 years $[1,4]$. 
The high incidence along with the remarkable recurrence rates makes urolithiasis a serious social and economical problem for the societies. Although the symptoms and consequences are not life threatening in the majority of patients, stones in the urinary tract form a major cause of morbidity, hospitalization and days lost from work [2]. The number and the size of stones may increase in patients with recurrent stone disease making the treatment costs higher than the primary cases $[5,6]$. Considering the increasing incidence and remarkable recurrence rates into account; epidemiological studies focusing on factors responsible for the formation of different stone types and also the natural course of the disease (i.e. recurrence rates) gained more importance than ever. Among these factors; although family history positivity has been subjected to a number of studies in recent years [7-10], the question of a familial predisposition towards stone formation and recurrence in urolithiasis has not been sufficiently examined.

The aim of this study was to evaluate the possible effect of a positive family history on the age at the onset of urinary stone disease and the frequency of subsequent symptomatic episodes relating to the disease.

\section{Patients and methods}

Between March 2006 and April 2009, patients with either a newly diagnosed or a previously documented stone disease were included into the study program. During the study program, all of the patients were evaluated with respect to their history of stones. They were required to fill in a questionnaire and divided into two groups according to the positive family history of stone disease; group I included patients with positive family history for urinary calculi and group II included patients without family history. The presence of previous stone disease, as well as the family history positivity has been confirmed from the documents available either from our own institution or from the other medical institutions where the previous diagnostic examinations were carried out. Depending on the data obtained from questionnaires, all patients were evaluated in detail with respect to the age at the onset of the stone disease, stone passage and interventions over time, time to first recurrence (time interval between the onset of the disease and the first recurrence), number of total stone episodes and recurrence intervals. In addition, the number and the type of family members of the patients in group I suffering from urolithiasis were noted. Stone episode was defined as the clinical and/or radiological finding recorded either at the diagnosis of a new stone formation or during the passage of an existing stone. Patients with one or more previous episodes of stone disease were defined as recurrent stone formers.
The data were analyzed using the SPSS 15.0 program. Parametric values were evaluated with $t$ test and non-parametric descriptive values were tested with $\chi^{2}$ or Fischer's exact test for statistical significance.

Study protocol has been approved by the ethics committee of the faculty and signed consent was obtained from all subjects before interview.

\section{Results}

1,595 patients suffering from urolithiasis with the mean age of 41.7 (14-69 years) were evaluated with respect to their past history of the disease. Male:female ratio was 1.38 (926:669).

Although group I consisted of 437 patients with a positive family history; group II consisted of 1,158 patients without any positive family history. There was no statistically significant difference between the mean age of two groups $(P=0.09)$ (Table 1$)$. When both genders in group I were analyzed separately, female patients tended to have higher rate of family history positivity than males (F/M: 1.45) (Table 1). Table 1 summarizes the evaluation of the family members with documented urolithiasis.

Comparative evaluation of the age at the onset of the disease between the two groups did reveal that stone formation occurs at younger ages in patients with positive family history $[P=0.01$ (males), $P=0.01$ (females) $]$ and the mean age of onset of the disease was lower in males than females in group $\mathrm{I}(P=0.01)$ (Table 2). In addition to being affected by stone formation at younger ages; patients in group I had stone episodes relatively more often from the onset of the disease $[P<0.01$ ( $2-4$ episodes), $P<0.01$ ( $\geq 5$ episodes) $]$ where male patients were associated with higher number of stone episodes $(P=0.01)$ (Table 3$)$. Although the majority of the patients in group II did have only one stone episode without any further recurrence; the percentage of patients having 2-5 recurrences as well as more than five recurrences were significantly higher in patients with positive family history (Table 3). Mean time interval between recurrences was noted to be significantly shorter in the same group of patients $(25.4 \pm 9.6$ months in males and $27.3 \pm$ 9.7 in females) when compared with patients in group II $(34.6 \pm 12.3$ months in males and $33.9 \pm 11.4$ months in females) $[P<0.01$ (males), $P=0.02$ (females)] (Table 4).

Although patients in group I tended to have slightly higher percentage of multiple kidney stones, there was no statistically significant difference between the location, size and the number of stones in the two groups $[P=0.21$ (kidney stones), $P=0.14$ (ureteral stones), $P=0.8$ (bladder stones)]. The chemical composition of the stones was available in 949 patients $(59.4 \%)$. Although it was difficult to obtain the data from the evaluated files, most stones in the 
Table 1 Evaluation of positive family history status with respect to the members affected

\begin{tabular}{|c|c|c|}
\hline Total number of patients & 1,595 (males 926, females 669) & $\mathrm{M} / \mathrm{F} 1.38$ \\
\hline Age range (mean) & 14-69 (mean 41.7 years) & \\
\hline Age at the onset of the stone disease & $\begin{array}{l}\text { Males } 31.7 \pm 10.2 \text { years } \\
\text { Female } 37.5 \pm 12.8 \text { years }\end{array}$ & Overall $34.0 \pm 13.4$ years \\
\hline \multicolumn{3}{|c|}{ Presence of positive family history $(n=437,27 \%)$} \\
\hline Male & $178 / 437: 40.7 \%$ & $\begin{array}{l}\text { Age range (mean years): } \\
3-58(28.4)\end{array}$ \\
\hline Female & $259 / 437: 59.3 \%$ & $\begin{array}{l}\text { Age range (mean years): } \\
\quad 4-59(31.2)\end{array}$ \\
\hline \multicolumn{3}{|c|}{ Evaluation of first-degree relatives in group I } \\
\hline Mother or father & $216(49.4 \%)$ & M/F: 94/122 \\
\hline Mother and father & $115(26.3 \%)$ & $\mathrm{M} / \mathrm{F}: 65 / 50$ \\
\hline Mother, father and one sibling & $61(13.9 \%)$ & M/F: 25/36 \\
\hline Sibling (brother or sister) & $45(10.3 \%)$ & M/F: $24 / 21$ \\
\hline \multicolumn{3}{|c|}{ Evaluation of second degree relatives in group I } \\
\hline \multirow[t]{2}{*}{ Aunt, uncle and cousin } & $157(35.9 \%)$ & M/F: 88/69 \\
\hline & Positive family history & Negative family history \\
\hline \multicolumn{3}{|l|}{ Comparison of two groups } \\
\hline Number of patients & 437 & 1,158 \\
\hline Number of male patients & 178 & 748 \\
\hline Number of female patients & 259 & 410 \\
\hline Age at the onset & $34.0 \pm 13.4$ years & $32.9 \pm 10.9$ years \\
\hline $\begin{array}{l}\text { Patients with the onset of the } \\
\text { disease before the age of } 15\end{array}$ & $67 / 437(15.3 \%)$ & $127 / 1,158(10.9 \%)$ \\
\hline
\end{tabular}

Table 2 Evaluation of the mean age of patients in both the groups at first onset of the disease

\begin{tabular}{|c|c|c|c|}
\hline & $N$ & Males & Females \\
\hline \multicolumn{4}{|c|}{ Mean age at the onset of the disease (years) } \\
\hline Whole group & 1,595 & $31.7 \pm 10.2(3-69)$ & $37.5 \pm 12.8(5-64)$ \\
\hline $\begin{array}{l}\text { Positive family } \\
\text { history }\end{array}$ & 437 & $24.8 \pm 9.4(3-58)$ & $28.3 \pm 9.7(4-59)$ \\
\hline No family history & 1,158 & $32.6 \pm 11.9(6-64)$ & $33.8 \pm 10.2(7-66)$ \\
\hline
\end{tabular}

Table 3 Evaluation of stone episodes in both groups

\begin{tabular}{llll}
\hline $\begin{array}{l}\text { Stone } \\
\text { episodes }\end{array}$ & $\begin{array}{l}\text { General } \\
(\%)\end{array}$ & $\begin{array}{l}\text { Positive } \\
\text { history }(n=437)\end{array}$ & $\begin{array}{l}\text { Negative history } \\
(n=1,158)\end{array}$ \\
\hline 1 & $921(57.7)$ & $\begin{array}{c}202(46.2 \%) \\
\text { M/F: } 108 / 94(1.14)\end{array}$ & $719(62.1 \%)$ \\
$2-4$ & $439(27.5)$ & $\begin{array}{c}149(34.1 \%) \\
\text { M/F: } 89 / 60(1.48)\end{array}$ & $290(25.1 \%)$ \\
5 and more & $235(14.7)$ & $86(19.7 \%)$ & $149(12.8 \%)$ \\
& & M/F: $51 / 35(1.45)$ & \\
\hline
\end{tabular}

two groups were calcium stones (82\% in group I and $84 \%$ in group II).

When we evaluated the previous history of stone removal procedures in both the groups, the number of interventions were relatively higher in group I. Majority of
Table 4 Mean time interval period between the stone episodes in both the groups of patients

\begin{tabular}{lccc}
\hline & $N$ & Males & Females \\
\hline \multicolumn{2}{l}{ Mean time interval between recurrences (months) } \\
Whole group & 1,595 & $32.6 \pm 10.4$ & $30.8 \pm 9.84$ \\
& & $(13-54)$ & $(15-62)$ \\
Positive family & 437 & $25.4 \pm 9.66$ & $27.3 \pm 9.72$ \\
history & & $(11-52)$ & $(12-46)$ \\
No family history & 1,158 & $34.6 \pm 12.3$ & $33.9 \pm 11.4$ \\
& & $(16-62)$ & $(17-58)$ \\
\hline
\end{tabular}

the patients in group II did not have previous stone removal procedures $(P=0.02)$ (Table 5).

A search for associated comorbidities (hypertension, diabetes, hypercholesterolemia, etc.) revealed a relatively higher coincidence of such pathologies in group I patients when compared with the patients in group II (30.4 and 18.9\%, respectively).

\section{Discussion}

Increasing incidence and considerable recurrence rates along with severe renal functional consequences make urolithiasis a surgical and a medical problem which needs a 
Table 5 Evaluation of previous surgery and the type of the procedures in both groups of patients

\begin{tabular}{lcll}
\hline Previous intervention & $\begin{array}{l}\text { General } \\
(n=1,595) \\
(\%)\end{array}$ & $\begin{array}{l}\text { Positive } \\
\text { history } \\
(n=437)(\%)\end{array}$ & $\begin{array}{l}\text { Negative } \\
\text { history } \\
(n=1,158)(\%)\end{array}$ \\
\hline Pyelo/nephrolithotomy & $42(2.6)$ & $29(6.7)$ & $27(2.2)$ \\
Cystolithotomy & $34(2.1)$ & $15(3.6)$ & $19(1.5)$ \\
PCNL & $168(10.6)$ & $94(21.5)$ & $118(10.1)$ \\
Ureteroscopy & $114(7.1)$ & $72(16.4)$ & $120(10.3)$ \\
SWL & $203(12.7)$ & $113(25.9)$ & $196(16.8)$ \\
None & $1,034(64.8)$ & $114(25.9)$ & $684(59.1)$ \\
\hline
\end{tabular}

prompt diagnosis and appropriate management at all ages $[11,12]$. Keeping these facts in mind, in addition to the successful surgical removal procedures; attempts have been made to limit the new stone formation after the first stone episode in stone formers.

In this regard; identification of recurrent stone formers is a crucial step for a proper treatment planning and also important as a solution for future problems induced by the disease [13]. Different studies reported recurrence rates of patients with urolithiasis as high as $30-50 \% 5$ years after the first episode $[14,15]$ and calcium oxalate stones are most likely to re-form where recurrence rates have been reported to be $40 \%$ at 3 years, $74 \%$ at 10 years and $98 \%$ at 25 years [16-18]. Related with this subject, Strohmaier et al. [19] reviewed the literature well and reported 30-40\% recurrence rates where the highest recurrence probability was during the first 4 years. Thus, associated morbidities and increasing socioeconomic costs of urolithiasis made it important to identify the patients at risk for close follow-up and early proper management planning [6, 12, 17, 20-22].

Management of this problem is increasingly relying on inhibiting stone growth and preventing formation of new stones; such a prophylactic approach requires identification of factors which predispose patients to urinary stone formation and several epidemiological factors on this aspect have been evaluated. Among the factors evaluated so far; studies focused on age, gender, ethnicity, past medical history, educational and social level along with the profession, dietary status and inherent genetic predisposition [1, 6, 23].

A variety of publications have focused on the possible effect of positive family history for the onset and recurrence as well as for the prevalence of urinary stones. However, the exact relationship between the familial predisposition and the stone formation in primary urolithiasis has been incompletely analyzed. Positive family history has been reported to be present in $17-37 \%$ of patients with stone disease when compared with 4-22\% of normal healthy control subjects $[7,10]$. In a well-designed epidemiological study, about $25 \%$ of patients with urinary stones have been found to be associated with a positive family history [8]. In another study, it was demonstrated that stone-forming patients with positive family history were affected by the disease at younger ages [9]. In a survey carried out in 380 patients in an outpatients' stone clinic, a majority of the patients with a documented family history, had experienced frequent recurrences when compared with the others. While in $55.4 \%$ of patients at least one first-degree relative suffered from renal stones; positive family history was more common in females $(64.7 \%)$ than males $(51.0 \%)$ and in those who had multiple recurrences [7]. In an evaluation of 214 calcium stone patients and 428 age and sex-matched controls; the authors observed a higher frequency of stone episodes among the first-degree relatives of stone patients compared with the relatives of controls. A family history of renal stones was more common among female (45\%) and male patients $(31 \%)$. Finally, the parents and siblings of renal stone patients with positive family history were found to have more calculi than the corresponding relatives of their spouses [24].

In the present study, we aimed to evaluate the possible effect of positive family history on recurrent stone formation and compare the data with stone-forming patients without any positive family history. The overall incidence of positive family history in stone-forming patients was $27 \%$. Female gender seemed to have higher incidence of positive family history than males. Male gender tended to be afflicted by the disease at younger ages than females, which was more pronounced for the cases revealing a positive family history. This finding is important because the involvement of one or more members of the family with stone disease may be a good predictor for the onset of the disease at younger ages in next generations. Another important parameter was the number of stone recurrences and the interval between these episodes. Evaluation of the patients with positive family history did clearly show that these patients tended to have higher recurrence rates in relatively shorter periods. Therefore, this finding makes the close follow-up of such cases mandatory. A total of $53.8 \%$ of patients with positive family history did have more than two stone episodes at the same period which was significantly higher than the patients without any family history.

Separate evaluation of both sexes clearly showed that male gender was associated with higher number of stone episodes which might be caused by an earlier onset of the disease in that gender, possibly also associated with an increased biochemical risk. This finding has also been found to be in accordance with the data of many studies regarding the recurrence rates which in turn may emphasize the potential inhibitory role of female hormones in urinary stone formation $[25,26]$.

In the light of all these findings, the higher incidence of recurrences and the early onset of the disease in patients with family history of urolithiasis may lead the clinicians 
focus on genetic factors playing an important role in such patients as well as families.

One obvious limitation of our study is the lack of 24-h urine chemistry data. On the other hand, the retrospective nature of the study constitutes a minor limitation in our opinion. However, considering the limited number of the studies carried out so far and the problems in collecting data from the patients for such evaluations (i.e. follow-up of patients with respect to keeping them under dedicated medical therapy) may make a prospective study more difficult for the physicians working in this field of urology.

\section{Conclusions}

In the light of the multifactorial nature of urolithiasis, our findings show that in addition to dietary and lifestyle factors, a positive family history may also affect the onset as well as the course of urinary stone disease. Early onset of urinary stone formation along with the frequent stone episodes in such cases may make the positive family history predictive of the course of the stone disease and, therefore, these patients should be followed up closely to prevent future recurrences. We also believe that as an important epidemiological factor, a positive family history will add a new perspective to the evaluation and management of patients with urinary stone disease. This might be of particular value for those with severe recurrent stone formation.

Open Access This article is distributed under the terms of the Creative Commons Attribution Noncommercial License which permits any noncommercial use, distribution, and reproduction in any medium, provided the original author(s) and source are credited.

\section{References}

1. Bartoletti L, Cai L, Mondaini N, Melone F, Travaglini F, Carini M, Rizzo M (2007) Epidemiology and risk factors in urolithiasis. Urol Int 79:3-7

2. Stamatelou KK, Francis ME, Jones CA, Nyberg LM, Curhan GC (2003) Time trends in reported prevalence of kidney stones in the United States: 1976-1994. Kidney Int 63:1817-1823

3. Coe FL, Keck J, Norton ER (1977) The natural history of calcium urolithiasis. JAMA 238:1519-1523

4. Gambaro G, Santos R, Rao N (2004) Nephrolithiasis: Why doesn't our 'learning' progress? Eur Urol 45:547-556

5. Skolarikos A, Alivizatos G, de la Rosette J (2006) Extracorporeal shock wave lithotriphsy 25 years later: complications and their prevention. Eur Urol 50:981-990

6. Unal D, Yeni E, Verit A, Karataș OF (2005) Prognostic factors effecting on recurrence of urinary stone disease: a multivariate analysis of everyday patient parameters. Int Urol Nephrol 37(3):447-452
7. Ljunghall S, Danielson BG, Fellström B, Holmgren K, Johansson G, Wikström B (1985) Family history of renal stones in recurrent stone patients. Br J Urol 57(4):04-370

8. Curhan GC, Willett WC, Rimm EB, Stampfer MJ (1997) Family history and risk of kidney stones. J Am Soc Nephrol 8(10):15681573

9. Ahmadi Asr Badr Y, Hazhir S, Hasanzadeh K (2007) Family history and age at the onset of upper urinary tract calculi. Urol $\mathrm{J}$ 4(3):142-145 Discussion 5-6

10. Ljunghall S (1979) Family history of renal stones in a population study of stone formers and healthy subjects. Br J Urol 51:249-252

11. Lancina Martín JA, Novás Castro S, Rodríguez-Rivera García J, Ruibal Moldes M, Blanco Díez A, Fernández Rosado E, Barbagelata López A, González Martín M (2004) Age of onset of urolithiasis: relation to clinical, metabolic risk factors. Arch Esp Urol 57(2):119-125

12. Trinchieri A, Ostini F, Nespoli R, Rovera F, Montanari E, Zanetti GA (1999) Prospective study of recurrence rate and risk factors for recurrence after a first renal stone. J Urol 162(1):27-30

13. Long Lo, park S (2007) Update on nephrolithiasis. Minerva Urol Nephrol 59(3):317-325

14. Johnson CM, Wilson DM, O'Fallon WM (1979) Renal stone epidemiology: a 25 year study in Rochester, Minnesota. Kidney Int 16:624-631

15. Ljunghall S, Danielson BG (1984) A prospective study of renal stone recurrences. Br J Urol 56:122-124

16. Lewandowski S, Rogers AL (2004) Idiopathic calcium oxalate urolithiasis: risk factors and conservative treatment. Clin Chim Acta 345:17-34

17. Robertson WR (1999) The economics of urinary stone management. In: Borghi L, Meschi T, Briganti A, Schianchi T, Novarini A (eds) Kidney stones. 8th Europan symposium on urolithiasis, vol 1. Editorial Bios, Cosenza, pp 169-172

18. Pareek G, Steele TH, Nakadas Y (2005) Urological intervention in patients with cystinuria is decreased with medical compliance. J Urol 174:2250-2252

19. Strohmaier WL et al (2000) Course of calcium oxalate stone disease without treatment: what can we expect? Eur Urol 37(3):339-344

20. Strohmaier WL, Hormann M (2000) Economic aspects of urolithiasis and metaphylaxis in Germany. Urolithiasis 406-409

21. Chandhoke PS (2002) When is medical prophylaxis cost-effective for recurrent calcium stones? J Urol 168:937-940

22. Krepinsky J, Ingram AJ, Churchill DN (2000) Metabolic investigation of recurrent nephrolithiasis: compliance with recommendations. Urology 50(6):915-920

23. Ekane S, Wildschutz T, Simon J, Schulman CC (1997) Urinary lithiasis: epidemiology and physio-pathology (review). Acta Urol Belg 65:1-8

24. Trinchieri A, Mandressi A, Luongo P, Coppi F, Pisani E (1988) Familial aggregation of renal calcium stone disease. J Urol 139(3):478-481

25. Iguchi M, Takamura C, Umekawa T, Kurita T, Kohri K (1999) Inhibitory effects of female sex hormones on urinary stone formation in rats. Kidney Int 56(2):479-485

26. Yagisawa T, Ito F, Osaka Y, Amano H, Kobayashi C, Toma H (2001) The influence of sex hormones on renal osteopontin expression and urinary constituents in experimental urolithiasis. J Urol 166(3):1078-1082 